\title{
Invasive Breast Carcinoma
}

National Cancer Institute

\section{Source}

National Cancer Institute. Invasive Breast Carcinoma. NCI Thesaurus. Code C9245.

A carcinoma that infiltrates the breast parenchyma. The vast majority are adenocarcinomas arising from the terminal ductal lobular unit (TDLU). Often, the invasive adenocarcinoma co-exists with ductal or lobular carcinoma in situ. It is the most common carcinoma affecting women. 